\title{
(6) OPEN ACCESS \\ Pulmonary hypertension in children with congenital heart disease (PAH-CHD, PPHVD-CHD). Expert consensus statement on the diagnosis and treatment of paediatric pulmonary hypertension. The European Paediatric Pulmonary Vascular Disease Network, endorsed by ISHLT and DGPK
}

\author{
Rainer Kozlik-Feldmann, ${ }_{1}^{1}$ Georg Hansmann, ${ }^{2}$ Damien Bonnet, ${ }^{3}$ Dietmar Schranz, ${ }^{4}$ \\ Christian Apitz, ${ }^{5}$ Ina Michel-Behnke ${ }^{6}$
}

For numbered affiliations see end of article.

\section{Correspondence to} Dr Rainer Kozlik-Feldmann, Department of Paediatric Cardiology, University Heart Center, University Medical Center Hamburg-Eppendorf, Martinistr. 52, Hamburg 20246, Germany;

r.kozlik-feldmann@uke.de

This article is a product of the writing group of the European Paediatric Pulmonary Vascular Disease (PVD) Network (Writing Group Chair: $G$ Hansmann, Writing Group Co-Chair: C. Apitz); ISHLT, International Society of Heart and Lung Transplantation; DGPK, German Society of Paediatric Cardiology.

Received 10 July 2015 Revised 11 October 2015 Accepted 14 October 2015
CrossMark

To cite: Kozlik-Feldmann $R_{\text {, }}$ Hansmann G, Bonnet D, et al. Heart 2016;102: ii42-ii48.

\section{ABSTRACT}

Pulmonary arterial hypertension associated with congenital heart disease (PAH-CHD) is a complex disease that presents with a broad spectrum of morphological and haemodynamic findings of varying severity. Recently, the aspect of paediatric pulmonary hypertensive vascular disease (PPHVD) has been introduced to expand the understanding of the full spectrum of pulmonary hypertension and increased pulmonary vascular resistance. Evaluation and treatment of PAH-CHD/ PPHVD-CHD can be divided into in different topics. First, defining criteria for operability and initiation of advanced therapies preoperatively and postoperatively is an unresolved issue. Second, management of Eisenmenger syndrome is still an important question, with recent evidence on the severity of the disease and a more rapidly progressive course than previously described. Third, the Fontan circulation with no subpulmonary ventricle requires a distinct discussion, definition and classification since even a mild rise in pulmonary vascular resistance may lead to the so-called failing Fontan situation. Patients with CHD and single-ventricle physiology (Fontan/total cavopulmonary anastomosis) require a particularly stepwise and individualised approach. This consensus statement is on the current evidence for the most accurate evaluation and treatment of increased pulmonary artery pressure and resistance, as well as ventricular dysfunction, in children with congenital heart defects, and provides according practical recommendations. To optimise preoperative and postoperative management in patients with $\mathrm{PAH}-\mathrm{CHD}$, diagnostic and treatment algorithms are provided.

\section{INTRODUCTION}

Pulmonary hypertension (PH) associated with congenital heart disease (CHD) is commonly associated with left-to-right shunt defects, or left heart obstructive disease causing postcapillary $\mathrm{PH}^{1}{ }^{1}$ However, such simple grouping of CHD features does not reflect the heterogeneity of paediatric $\mathrm{PH}$ in the setting of CHD. The most recent update from the 5th World Symposium on PH (WSPH) in Nice 2013 proposed a more detailed approach for
$\mathrm{PH}$ associated with $\mathrm{CHD} .^{2}$ CHDs with volume load to the pulmonary arteries have been grouped in class 1.4.4 'Congenital heart diseases' (see the consensus statement on 'diagnostics, monitoring, outpatient care' $\left.{ }^{3}\right)$. $\mathrm{PH}$ associated with left heart congestive diseases can now be found in class 2.4 'Congenital/acquired left heart inflow/outflow tract obstruction and congenital cardiomyopathies'. And finally, segmental $\mathrm{PH}$ that does not affect all segments of the lung is allocated to group 5 .

The difficulty in the management of $\mathrm{PH}$ in paediatric CHD is further augmented by the complexity of the underlying CHD and the frequent comorbidities. Certainly, comorbidities that include prematurity, neonatal lung diseases (bronchopulmonary dysplasia and lung hypoplasia), chromosomal anomalies and polymalformations syndromes may puzzle the healthcare provider in the evaluation of the aetiology and pathophysiology of elevated pulmonary vascular resistance (PVR) in CHD. In order to meet the complexity of paediatric $\mathrm{PH}$ with increased PVR, a more detailed and age-dependent classification has been proposed by the Paediatric Taskforce of the Pulmonary Vascular Research Institute (Panama 2011) that expanded the term pulmonary arterial hypertension (PAH) to paediatric pulmonary hypertensive vascular disease (PPHVD). ${ }^{4-6}$

In the Netherlands, the incidence and prevalence of idiopathic pulmonary arterial hypertension (IPAH) was estimated to be 0.7 and 4.4 per million children, respectively, whereas $\mathrm{PAH}$ associated with congenital heart disease (PAH-CHD) had an assumed incidence of 2.2 and a prevalence of 15.6 per million.

Pathophysiology of CHD with intra-cardiac and extra-cardiac shunts may differ greatly in pretricuspid versus post-tricuspid lesions (ie, proximal or distal to the subpulmonary atrioventricular valve in the bloodstream).

Pre-tricuspid shunts are left-to-right (or bidirectional) shunts at a low-pressure level, which lead to volume load on the right ventricle (RV) and pulmonary circulation, without immediate or midterm increase of pulmonary arterial pressure (PAP). In pre-tricuspid lesions, the development of 
PAH-pulmonary vascular disease (PVD)/PPHVD may occur beyond the forth decade of life in $6-17 \% .{ }^{8}$ The risk of developing PVD is not only associated with the size of the atrial septal defect (ASD) but also dependent on the compliance of the RV $(\rightarrow$ magnitude of the left-to-right shunt). The same considerations apply to partial anomalous pulmonary venous return (PAPVR). The volume load of the pulmonary circulation will be strongly influenced by additional left heart lesions and left ventricular dysfunction. However, Eisenmenger syndrome in adults with ASD is rare and was estimated to occur in only $2 \%$ of patients. ${ }^{9}$

Post-tricuspid lesions are left-to-right shunts at a high-pressure level, which lead to volume load on the left ventricle and pulmonary circulation. If the post-tricuspid defects are large enough, the pulmonary pressure will increase to systemic blood pressure level (pressure-unrestrictive ventricular septal defects (VSDs)). In post-tricuspid lesions, the development of PAH-PVD/PPHVD will occur during the first years of life. Untreated, $\approx 50 \%$ of the patients with post-tricuspid lesions will develop suprasystemic PVR with shunt reversal to a right-to-left shunt through the preformed shunt lesions, that is, the so-called Eisenmenger complex. While adults with Eisenmenger-PAH have a better survival than those with idiopathic/heritable PAH, children with PAH-CHD and PVD (ie, PPHVD) have a 5-year mortality that appears to be comparable to those with idiopathic/ heritable PAH $(29 \%$ vs $25 \%) .{ }^{10}$ The severity of adult PAH-CHD tends to be underestimated because the apparent survival is related to the immortal bias selection of patients in reported registries. ${ }^{1}$

The particular haemodynamics of the Fontan circulation is fragile (total cavopulmonary connection: no subpulmonary ventricle, systemic veins surgically connected to the pulmonary circulation). In fact, there are potentially several reasons for a 'failing Fontan' situation to occur. The single-ventricle dysfunction, chronically elevated central venous pressure, elevated PVR (for passive pulmonary blood flow) or obstructions in the venous or arterial pathway may cause heart failure or specific complications such as plastic bronchitis or protein-losing enteropathy. 'Failing Fontan' patients do not fulfil standard criteria for PH but may have an increased PVR, as judged by the transpulmonary pressure gradient. ${ }^{2}$ There has been recent evidence of a potential clinical response to specific PAH therapies in Fontan patients, which needs further exploration before therapeutic recommendations can been made. ${ }^{2}$ The aim of this article is to present the current evidence for the most accurate evaluation and treatment of PAH-CHD, PHVD associated with $\mathrm{CHD}$ in children and adolescents, including according consensus recommendations.

\section{METHODS}

The recommendations given in table 1 relate to the grading system currently suggested by the European Society of Cardiology (ESC) and the American Heart Association, and was based on paediatric data only (class, level of evidence). The grading and voting process within the writing group is outlined in this issue. ${ }^{11}$ Computerised searches of the PubMed/ MEDLINE bibliographic database from 1990 to June 2015 were conducted. The developer searched using the terms 'paediatric pulmonary hypertension', 'congenital heart disease', 'pulmonary arterial hypertension', 'vasoreactivity in pulmonary hypertension', 'cavopulmonary anastomosis pulmonary hypertension', 'Fontan circulation and pulmonary vascular disease', 'operability in congenital heart disease in children', 'nitric oxide in pulmonary hypertension in children', 'Eisenmenger syndrome and pulmonary hypertension'.

\section{DIAGNOSIS OF PULMONARY HYPERTENSION ASSOCIATED WITH CONGENITAL HEART DISEASE}

A modified clinical classification of PAH associated with CHD, based on the most recent WSPH recommendations $(2013){ }^{2}$ is given in box 1. Detailed recommendations on the evaluation of patients with $\mathrm{PAH}$ by echocardiography are given by Koestenberger et al. ${ }^{34}$ within this issue. Echocardiography is the most valuable tool to describe morphology, haemodynamics and ventricular function. In addition, an estimation about precapillary or postcapillary PH can be made. Even though cardiac catheterisation is the gold standard for diagnosing $\mathrm{PH}$ with and without PVD, echocardiography may predict PAP and PVR and is a valuable routine tool. In complex $\mathrm{CHD}$, or suboptimal echocardiographic windows, cardiac MRI or chest CT may be performed to determine ventricular mass and volumes, valvular regurgitation or any obstruction in single or biventricular circulation. ${ }^{35}$ Furthermore, patients with $\mathrm{PH}$ should be evaluated for concomitant diseases (heart, lung, abdomen) with implications on management and prognosis, especially in patient groups with comorbidities increasing the risk of developing PPHVD. ${ }^{3}$

\section{Surgery and operability of patients with PAH-CHD and biventricular circulation}

For correctable CHD, timely surgical repair is paramount

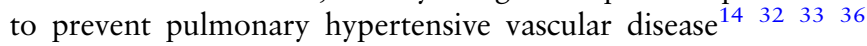
(figure 1). Consequently, corrective or palliative surgery with CHD and significant left-to-right shunt is performed mostly in the first six months of life to prevent persisting or evolving pressure load on the pulmonary vasculature. Nevertheless, PAH after surgical repair of CHD has been reported in $7.4 \%$ of adult patients with CHD. ${ }^{37}$ Today, there is no clear consensus on criteria for operability in left-to-right shunts with elevated PVR. However, operability is of utmost importance as it has been shown that prognosis of postoperative PAH-CHD, which can be prevented by timely shunt closure in the majority of cases, is identical or worse than that of IPAH. ${ }^{38}$ No consensus exists on the management of $\mathrm{PAH}$ in patients with $\mathrm{CHD}$ who do not meet operability criteria or who have persisting PAH after correction of the defect (box 1).

\section{So-called 'simple shunt defects'}

In 'simple' left-to-right shunt defects (ASD, VSD, patent ductus arteriosus (PDA)), which are diagnosed in neonates/infants with clinical signs of heart failure (due to volume overload and shunt related low systematic cardiac output) and normal oxygen saturation, cardiac catheterisation and acute vasoreactivity testing (AVT) can be omitted and patients should be referred for surgical shunt closure (figure 1). Undiagnosed CHD that is asymptomatic for years and does not present with $\mathrm{PAH}$ until adulthood, for example, ASD in the adult, represents a special entity and cannot be compared with an ASD in childhood. ${ }^{39}$ For those adult patients with pre-tricuspid left-to-right shunts (eg, ASD, PAPVR), complete assessment of pressures, oxygen transport and utilisation, and the derived calculated variables is mandatory before considering surgery. A combination of precapillary and postcapillary PH may be present especially in the adult with chronic PH, which requires expert decision-making in terms of surgery or medical treatment, or pharmacotherapy before surgery ('treat to close' concept, see Hansmann and Apitz ${ }^{40}$ ).

In post-tricuspid shunts ('simple': VSD, PDA; or more complex $\mathrm{CHD}$ that allows shunt closure), early surgical correction of $\mathrm{CHD}$ within the first two years of life is essential to avoid irreversible remodeling of the pulmonary vasculature. For patients with an 
Table 1 Recommendations on the evaluation and management of pulmonary hypertension (PH) in children and adolescents with congenital heart disease (PAH-CHD, PPHVD-CHD)

\begin{tabular}{|c|c|c|}
\hline Recommendations & $\mathrm{COR}$ & LOE \\
\hline $\begin{array}{l}\text { Children/adolescents with clinically confirmed CHD should undergo specific transthoracic echocardiographic (TTE) screening for pulmonary arterial } \\
\text { hypertension (PAH) and/or ventricular dysfunction. TTE cannot reliably distinguish between PAH with increased PVR (PPHVD) and without elevated } \\
\text { PVR }^{4} 12\end{array}$ & 1 & $\mathrm{C}$ \\
\hline $\begin{array}{l}\text { In children and adolescents with PAH/PPHVD-CHD, a complete diagnostic workup needs to be performed in order to determine whether PAH is } \\
\text { associated or causally related to concomitant CHD }\end{array}$ & 1 & C \\
\hline $\begin{array}{l}\text { Operability/catheter intervention: surgery or interventional closure for CHD with simple post-tricuspid shunts (VSD, PDA) and significant left-to-right } \\
\text { shunting should preferably be performed within the first six months of life }\end{array}$ & 1 & C \\
\hline $\begin{array}{l}\text { Children with PAH-CHD and significant left-to-right shunting, congestive heart failure (pulmonary congestion), failure to thrive and } \mathrm{SpO}_{2}>95 \% \text { (lower } \\
\text { extremities) can be considered 'operable' for shunt closure, however, perioperative PH crisis may occur }\end{array}$ & Ila & C \\
\hline $\begin{array}{l}\text { Children with PAH-CHD, significant left-to-right shunting and uncertainties regarding the PVR are recommended to undergo comprehensive right and left } \\
\text { heart catheterisation regardless of the patient's age }\end{array}$ & 1 & C \\
\hline $\begin{array}{l}\text { Operability: children with CHD and simple defects (VSD, PDA) beyond the typical date of surgery (see main text) or those with shunts and cyanosis should } \\
\text { undergo comprehensive right and left cardiac catheterisation (see figure } 1)^{1415}\end{array}$ & 1 & C \\
\hline $\begin{array}{l}\text { Children with PVRI }<6 \mathrm{WU} \times \mathrm{m}^{2} \text { and a PVR/SVR ratio }<0.3 \text { in the absence of additional risk factors are eligible for standard management/surgery/ } \\
\text { percutaneous interventional device closure }\end{array}$ & I & C \\
\hline Children with PVRI $\geq 6$ WU $\times m^{2}$ and a PVR/SVR ratio $\geq 0.3$ have to be evaluated by acute vasodilative testing (AVT) & 1 & C \\
\hline Operability in complex CHD has to be judged individually, considering age, size and type of lesions and associated syndromes & 1 & $\mathrm{C}$ \\
\hline $\begin{array}{l}\text { In children/adolescents with single-ventricle physiology, the haemodynamic threshold for operability pre-Fontan surgery is probably a mean TPG } \\
\leq 6 \mathrm{~mm} \mathrm{Hg}\end{array}$ & Ila & C \\
\hline $\begin{array}{l}\text { In clinically asymptomatic children/adolescents with single-ventricle physiology and total cavopulmonary connection (Fontan), a PVRI } \leq 3 \mathrm{WU} \times \mathrm{m}^{2} \text { and } \\
\text { mean TPG } \leq 6 \mathrm{~mm} \mathrm{Hg} \text { is consistent with acceptable haemodynamics }\end{array}$ & Ila & C \\
\hline $\begin{array}{l}\text { In children/adolescents with total cavopulmonary connection (Fontan) signs of increased PVRI and/or low Qp and/or hepatic congestion should undergo } \\
\text { complete diagnostic workup, including comprehensive cardiac catheterisation }\end{array}$ & Ila & C \\
\hline $\begin{array}{l}\text { In children/adolescents with total cavopulmonary connection (Fontan) and PHVD (TPG is }>6 \mathrm{~mm} \mathrm{Hg} \text { ), or those Fontan patients with symptoms irrespective } \\
\text { of haemodynamics, targeted PH therapies should be considered to improve exercise capacity }{ }^{4}\end{array}$ & Ila & C \\
\hline $\begin{array}{l}\text { In inoperable children/adolescents with Eisenmenger syndrome, targeted pharmacotherapy as single drug or combination therapy (sequential, upfront) } \\
\text { may be used, depending on WHO functional class and symptoms }{ }^{16}\end{array}$ & Ila & C \\
\hline $\begin{array}{l}\text { In inoperable children/adolescents with Eisenmenger syndrome, iron supplementation (orally, intravenous) may be administered if iron deficiency is } \\
\text { present }^{17-20}\end{array}$ & Ilb & C \\
\hline $\begin{array}{l}\text { In inoperable children/adolescents with Eisenmenger syndrome, supplemental oxygen may be considered to reduce symptoms, after careful examination } \\
\left(\text { when } \mathrm{PaO}_{2}<60 \mathrm{~mm} \mathrm{Hg}\right)^{21} 22\end{array}$ & Ilb & C \\
\hline $\begin{array}{l}\text { In inoperable children with Eisenmenger syndrome and neurological symptoms (headaches, TIA, stroke), phlebotomy may be indicated in severe } \\
\text { hyperviscosity syndrome (MCV >80 fl) }\end{array}$ & Ilb & C \\
\hline In inoperable children/adolescents with Eisenmenger syndrome, anticoagulation may be considered in the absence of hemoptysis ${ }^{23} 24$ & $\mathrm{llb}$ & C \\
\hline $\begin{array}{l}\text { In children/adolescents with PAH/PPHVD-CHD and left heart congestion either due to obstruction or secondary due to myocardial dysfunction, it is } \\
\text { recommended to perform full haemodynamic evaluation by comprehensive right and left heart catheterisation }{ }^{25-32}\end{array}$ & 1 & $C$ \\
\hline
\end{tabular}

additional (genetic) risk for PPHVD, PPHVD severity or postoperative persistent PPHVD, as in Down's syndrome, surgery should occur within the first six months of life in most instances. These typical dates of surgery indicating an optimal time frame to prevent persisting or progressive PAH-CHD are well accepted and should eliminate or decrease (eg, fenestrated VSD patch) the flow/ shear-stress related elevation of PAP and PVR. ${ }^{36} 41$

\section{Advanced PAH-CHD and Eisenmenger's syndrome}

There are patients with PAH-CHD (eg, from developing countries) who present beyond the optimal age for surgery when admitted for evaluation. In these cases, a complete evaluation of the pulmonary and systemic haemodynamics has to be performed. If the physiology is already that of the Eisenmenger syndrome, defect closure at this stage is associated with elevated mortality and should not be pursued. ${ }^{8}$ Patients with PAH-CHD without a right-to-left shunt who are responsive to $\mathrm{AVT}^{42}$ may have prolonged periods until they convert shunt direction and turn from pink to blue. Until now it has not been proven whether every patient with $\mathrm{PAH}-\mathrm{CHD}$, persisting post-tricuspid left-to-right shunt, and variable degree of PHVD-CHD, necessarily develops an Eisenmenger syndrome or whether there are two different diseases with variable susceptibility to medical treatment. ${ }^{17} 43$ Due to improved diagnostics and timely treatment, it can be expected that the Eisenmenger complex in patients with CHD will become a rare entity in advanced healthcare systems in the future.

\section{Postcapillary pulmonary hypertension}

Valvular heart disease, such as mitral stenosis, may lead to postcapillary PH but usually responds to surgical repair with gradual decrease and normalisation of pulmonary pressure, whereas in restrictive physiology of the ventricles associated with postcapillary $\mathrm{PH}$, reversibility of $\mathrm{PH}$ is less clear. The evaluation of these patients with predominantly postcapillary $\mathrm{PH}$ should follow the same recommendations of complete haemodynamic assessment (including AVT) as for PAH/PHVD-CHD in this issue, ${ }^{42}$ whether they occur isolated or in combination with lesions that may cause precapillary PH (ie, PAH). A subset of these patients with left heart obstruction and left atrial hypertension do have reactive pulmonary vasoconstriction. Such a situation characterised by predominantly postcapillary $\mathrm{PH}$ with a precapillary component is accompanied by a marked elevation of the diastolic pulmonary artery pressure and increased diastolic 
Box 1 Clinical classification of pulmonary arterial

hypertension associated with congenital heart disease (modified from Simonneau et $\mathrm{al}^{2}$ )

1. Eisenmenger's syndrome

- Includes all large intra-cardiac and extra-cardiac defects systemic-to-pulmonary shunts, which may progress with time to severe elevation of PVR and to reversal (pulmonary-to-systemic) or bidirectional shunting; cyanosis, secondary erythrocytosis and multiple organ involvement are usually present. Post-tricuspid shunts such as VSD, PDA and aortopulmonary window progress more frequently and earlier to severe pulmonary vascular disease, shunt reversal and Eisenmenger physiology, than pre-tricuspid shunt lesions (eg, ASD).

2. Pulmonary arterial hypertension associated with prevalent systemic-to-pulmonary shunts

- correctable*

- non-correctable

- Include moderate to large defects; PVR is mildly to moderately increased, systemic-to-pulmonary shunting is still prevalent, whereas cyanosis at rest is not a feature.

3. Pulmonary arterial hypertension with small/coincidental $\dagger$ defects

- Marked elevation in PVR in the presence of small cardiac defects, which themselves do not account for the development of elevated PVR; the clinical picture is very similar to idiopathic PAH. Defect closure is contraindicated.

4. Pulmonary arterial hypertension after correction of congenital cardiovascular defects

- Congenital heart disease is repaired, but PAH either persists immediately after correction or recurs/develops months or years after correction in the absence of significant postoperative haemodynamic lesions.

*With surgery or intravascular percutaneous procedure. tThe size applies to adult patients.

ASD, atrial septal defect; PAH, pulmonary arterial hypertension; PDA, patent ductus arteriosus; PVR, pulmonary vascular resistance; VSD, ventricular septal defect.

transpulmonary pressure gradient ( $>7 \mathrm{~mm} \mathrm{Hg}$ in adults) (for details, see Apitz et $a l^{42}$ ). The precapillary component is called 'reactive' $\mathrm{PH}$, and the combined condition was formerly often called 'out of proportion' PH. Possibly, this subgroup of patients with both precapillary and postcapillary $\mathrm{PH}$ develops more severe PVD with time. ${ }^{44}$

\section{Lung biopsy}

Lung biopsies in patients with PAH-CHD with advanced, most likely irreversible pulmonary hypertensive vascular disease show intimal proliferation and vessel narrowing associated with impaired endothelial cell apoptosis and antiapoptotic signaling from perivascular inflammatory cells. ${ }^{45}$ Because of the low likelihood of altering the diagnosis and treatment and the substantial risk of morbidity and mortality, open or thoracoscopic lung biopsies are not recommended for patients with PAH-CHD/ PHVD-CHD ${ }^{33}$ in most instances. However, in certain situations when PAP and PVR remains high or even worsen after shunt closure in patients with PAH-CHD, healthcare providers may consider lung biopsy in addition to chest CT to rule out or confirm additional parenchymal lung disease such as alveolar capillary dysplasia. ${ }^{46}$

\section{Acute vasoreactivity (AVT) testing in PAH/PHVD-CHD and implications for surgical repair}

AVT in paediatric PH includes inhalative nitric oxide (iNO), oxygen, iNO+oxygen and/or (ideally) inhalative iloprost $^{13} 25-28{ }^{47}$ (for details, see Apitz et al ${ }^{42}$ ). For patients with CHD, it has not been proven that AVT can predict longterm prognosis, neither has it been shown that cut-off values indicate absolute contraindications for surgery. Nevertheless, there has been an agreement to evaluate and predict risk for development or persistence of PAH early and late after surgery for CHD. ${ }^{13}$ While in biventricular circulations with pulsatile pulmonary flow the diagnostic mPAP limit of $<25 \mathrm{~mm} \mathrm{Hg}$ is valuable in children beyond neonatal age, the ratio of systolic and mean pulmonary artery pressures between the pulmonary and systemic circulation, and the ratio of PVR and systemic vascular resistance (SVR), especially in the young age group, are important for judgement of operability or heart transplantation. ${ }^{29}{ }^{48}$ Vasoreactivity testing covers the response to vasodilative drugs and, moreover, the discrimination of pulmonary endothelial dysfunction. 28 49

Based on the limited published clinical studies and our own experience, we suggest a structured catheterisation protocol and two separate definitions of positive AVT: (1) AVT to assess prognosis and indication for specific PH therapy and (2) AVT to assess operability of associated pulmonary hypertension (APAH) with CHD (ADAH-CHD). ${ }^{12}$ The AVT protocol and the latter definitions can be found in Apitz et al. ${ }^{42}$ The haemodynamic change that defines a positive response to AVT in PAH associated with a shunt defect (Qp:Qs >1.5; APAH-CHD-shunt) for children should be considered as a $>20 \%$ fall in PVR-index and PVR/SVR with respective final values $<6 \mathrm{WU} \times \mathrm{m}^{2}$ and $<0.3$. Nevertheless, operative safety in APAH-CHD with a shunt cannot be guaranteed (the approximate grey zone is PVRindex 6-8 WU $\times \mathrm{m}^{2}$, and PVR/SVR ratio $0.3-0.5$ ) and an element of clinical subjectivity is inevitable. Further investigation is warranted in selected populations, such as the growing number of children with CHD complicated by chronic lung disease of prematurity, ${ }^{46}$ and in the developing world where patients are more likely to present late with advanced pulmonary hypertensive vascular disease and often shunt reversal (right-to-left, ie, Eisenmenger syndrome).

\section{Postoperative pulmonary hypertension in patients with PAH-CHD}

If postoperatively elevated PAP suspicious for PHVD-CHD is observed early after surgical repair and is not thought to be transient with intensive care measures, ${ }^{50}$ comprehensive left and right heart catheterisation may be indicated to evaluate the need for specific PAH therapy. The latter invasive diagnostics is certainly indicated in late postoperative PAH-CHD, that is, years after surgery, be it persistent/progressive or 'de novo'.

\section{Transcatheter interventions and surgical treatment creating a right-to-left shunt}

Finally, innovative surgery and transcatheter interventions have been proven to be helpful in purposely turning $\mathrm{PAH}$ patients to Eisenmenger physiology: creating an interatrial communication $^{5152}$ and/or establishment of a Potts shunt (left pulmonary 


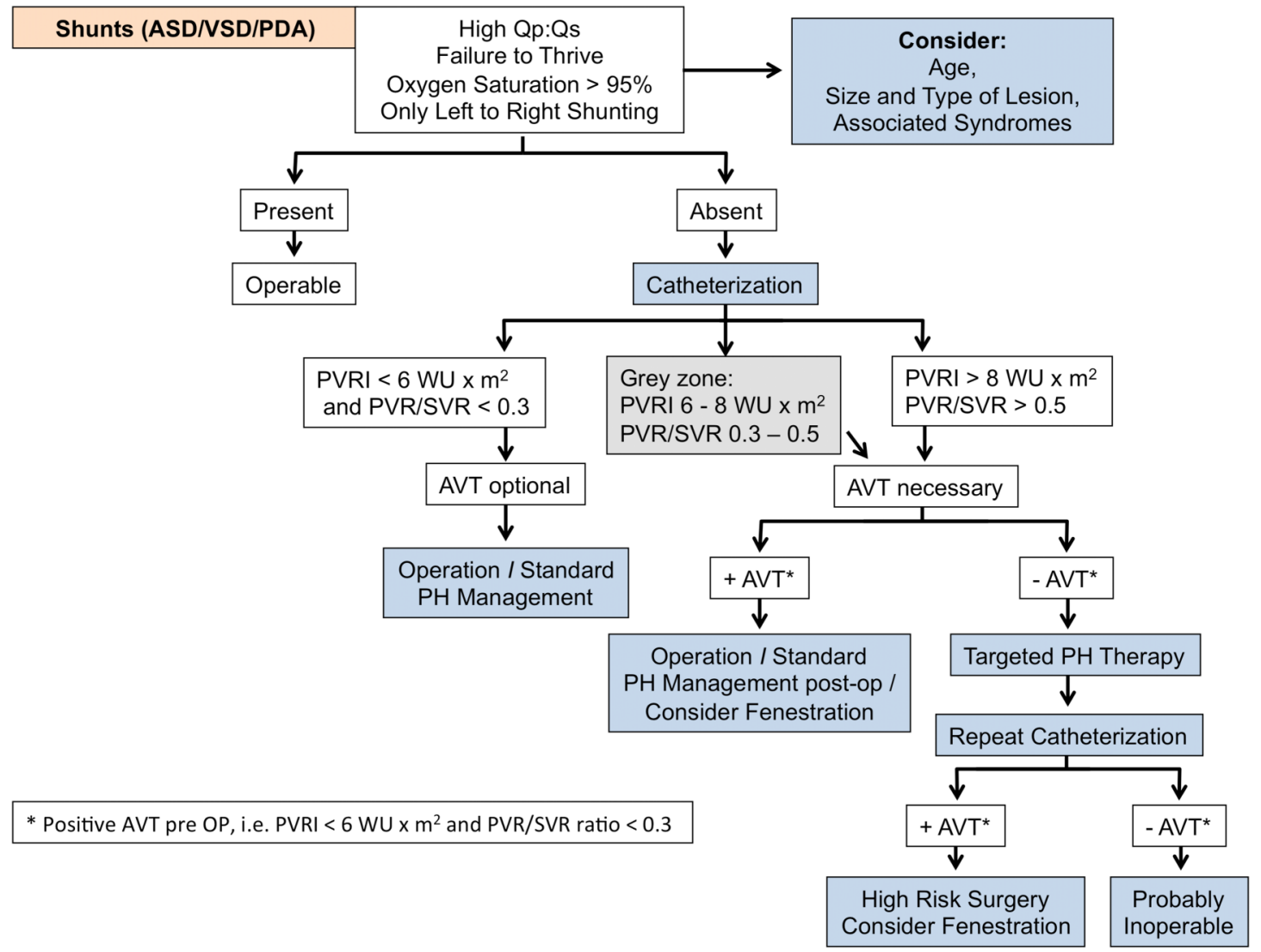

Figure 1 Algorithm for the management of patients with congenital heart disease associated with PAH/PPVD and congenital shunt lesions (modified from Lopes et $\mathrm{al}^{13}$ and the PVRI PAH-CHD taskforce (pdf on PVRI website). The indication for invasive diagnoses and eligibility for surgery/operability by comprehensive left and right heart catheterisation includes basic evaluation and AVT, the latter especially in the grey zone of forecast uncertainty. ASD, atrial septal defect; AVT, acute vasodilative testing; CHD, congenital heart disease; PAH, pulmonary arterial hypertension; PDA, patent ductus arteriosus; PH, pulmonary hypertension; pre OP, preoperatively; PVR, pulmonary vascular resistance; PVRI, PVR index; Qp, pulmonary blood flow; Qs, systemic blood flow; SVR, systemic vascular resistance; VSD, ventricular septal defect; WU, Wood units.

artery to descending aorta) or stenting an evident ductus arteriosus. $^{5253}$

Taken together, the criteria for closure of shunts in CHD are implemented within the WSPH Nice statements $(2013)^{2}$ and ESC/ERS guidelines (2015), ${ }^{33}$ but do not differentiate markedly between children and adults. Despite levels of evidence that do not exceed the level of expert opinion (C), a valuable algorithm for decision-making, including AVT, has been recently suggested by Lopes et al. ${ }^{13}$ We suggest a similar approach, following clinical, non-invasive and haemodynamic data (algorithm, figure 1). Whether AVT is able to predict long-term normalisation of pulmonary artery pressures and resistance cannot be ultimately answered.

\section{PULMONARY HYPERTENSIVE VASCULAR DISEASE IN THE CONTEXT OF SINGLE-VENTRICLE PHYSIOLOGY}

Patients with hypoplastic left ventricle (LV) or RV, and patients in whom the left and right heart cannot be separated for other reasons, undergo the (modified) Fontan procedure, leading to single-ventricle physiology and non-pulsatile pulmonary blood flow (no subpulmonary ventricle). In most cases, a first step is required to secure and define the pulmonary perfusion and to ensure an unobstructed systemic perfusion (stage 1 surgery, Norwood with classical BT-shunt or RV-PA shunt). This is followed by two cavopulmonary surgeries by connecting the systemic veins to the pulmonary arteries. First is a bidirectional anastomosis between superior vena cava (SVC) and pulmonary arteries (partial cavopulmonary anastomosis, syn. Glenn anastomosis) and in a second step the connection of the IVC to the pulmonary arteries (total cavopulmonary anastomosis (TCPC)/Fontan).

The measurements of mean transpulmonary pressure gradient $(\mathrm{mTPG}=\mathrm{mPAP}-\mathrm{LAP}$ mean) and PVR index (PVRI) are crucial for an appropriate selection of patients for the TCPC/Fontan circulation. Accepting the limitations of calculating and interpreting PVR in univentricular circulations, a mTPG of $\leq 6 \mathrm{~mm} \mathrm{Hg}$ with a PVRI $\leq 3 \mathrm{WU} \times \mathrm{m}^{2}$ probably marks the limit for completion of palliative separation of the pulmonary and systemic circulation in univentricular hearts. ${ }^{4}$ If the measurements are beyond these limits, it has been proposed to pre-treat with vasodilators such as PDE5-inhibitors or endothelin receptor antagonist to decrease PVR with the intention to reach the criteria for TCPC/Fontan palliation. However, clinical efficacy of such pharmacotherapy has not been proven.

There are no standards on how to properly estimate TCPC/ Fontan haemodynamics during cardiac catheterisation. It is unknown whether patients should be studied in general anaesthesia, sedation or local anaesthesia only. Transducer systems are sometimes unreliable in measuring the non-pulsatile pressure inside the pulmonary arteries. Additionally, aortopulmonary collaterals, residual antegrade flow from the ventricle and venovenous collaterals (to the pulmonary veins) or arteriovenous shunts make it difficult to estimate the correct Qp/Qs ratio.

However, standard procedures overcoming these questions have to be found because failure of TCPC/Fontan and decreased exercise tolerance in the absence of severe ventricular 
dysfunction or atrioventricular valve regurgitation may be attributed primarily to increased PVR. ${ }^{29}$

\section{PHARMACOTHERAPY OF PAH-CHD}

A brief overview of the actual treatment strategies with their effects on decrease of PVRI, ${ }^{54} 55$ improvement of quality of life and exercise tests has been published by others ${ }^{12}$ and is further outlined in our according expert consensus on paediatric $\mathrm{PH}$ therapy. ${ }^{40}$

For PAH-CHD patients in the grey zone of PVRI estimation (6-8 WU $\times \mathrm{m}^{2}$, figure 1), medical treatment prior to closure of the shunt defect may be pursued ('treat to close concept'), and closure of the defect can be considered if in a subsequent haemodynamic study the PVR index is $<6 \mathrm{WU} \times \mathrm{m}^{2}$. Convincing longterm data for this strategy remain scarce. If the patient remains in the grey zone of indexed PVR, a modified surgery with, for example, fenestrated defect closure may be considered. ${ }^{56}$

Most studies on 'targeted therapies' in PAH-CHD have been published for adult Eisenmenger patients ${ }^{17} 43 \quad 57-60$ and the ESC/ERS guidelines ${ }^{33}{ }^{61}$ cover this patient group, including supportive therapies. Iron supplementation has been shown to improve symptoms and secondary organ failure in adult Eisenmenger patients. ${ }^{18} 1962$

Beneficial haemodynamic effects of sildenafil and bosentan have been demonstrated also in failing Fontan circulations. ${ }^{63-68}$ Bosentan has been shown to improve exercise tolerance and oxygen saturation after Fontan surgery. ${ }^{69}$ Sildenafil improved max. oxygen consumption $\left(\mathrm{VO}_{2}\right.$ max.) and pulmonary blood flow in patients with Fontan circulation. Another randomised crossover study showed that sildenafil therapy improved exercise tolerance and ventilatory efficiency in Fontan patients. ${ }^{64}$ Data on the use of riociguat or selexipag in Fontan patients are currently lacking. A subgroup analysis of 35 patients with postoperative PAH-CHD treated with riociguat in the PATENT trial has been published. ${ }^{41}$ Upcoming results from an international registry (COMPERA-KIDS) will enhance our knowledge of medical treatment for the different settings of PAH-CHD.

\section{CONCLUSION}

In PAH-CHD, differentiation of the conditions that contribute to elevated pulmonary artery pressure or PVD is mandatory and requires appropriate $\mathrm{PAH}-\mathrm{CHD}$ classification. While the Eisenmenger complex in untreated lesions has become rare in advanced healthcare systems, persisting/progressive PAH even after timely surgery and low-pressure/high-resistance scenarios remain challenging. Patients with $\mathrm{CHD}$ and single-ventricle physiology (Fontan/TCPC) require a particularly stepwise and individualised approach. To optimise preoperative and postoperative management in patients with CHD, diagnostic and treatment algorithms are provided in the article.

\footnotetext{
Author affiliations

${ }^{1}$ Department of Paediatric Cardiology, University Heart Center, Medical University Hamburg, Hamburg, Germany

${ }^{2}$ Department of Paediatric Cardiology and Critical Care, Hannover Medical School, Hannover, Germany

${ }^{3}$ Unité Médico-Chirurgicale de Cardiologie Congénitale et Pédiatrique, Centre de référence Malformations Cardiaques Congénitales Complexes-M3C, Hôpital Necker Enfants Malades, APHP, Université Paris Descartes, Sorbonne Paris, France

${ }^{4}$ Department of Paediatric Cardiology, Paediatric Heart Center, University Hospital Giessen-Marburg, Giessen, Germany

${ }^{5}$ Division of Paediatric Cardiology, University Children's Hospital Ulm, Ulm, Germany ${ }^{6}$ Division of Paediatric Cardiology, Pediatric Heart Center, University Hospital for Children and Adolescents, Medical University Vienna, Vienna, Austria
}

Funding and competing interests $\mathrm{GH}$ currently receives grant support from the German Research Foundation (DFG and HA 4348/2-1), Fördergemeinschaft deutsche
Kinderherzzentren (W-H-001-2014) and Stiftung Kinderherz (2511-6-13-011). DB currently receives grants from the Agence Nationale de la Recherche and from the Fédération Française de Cardiologie and received fees for consulting, advisory boards and steering committee membership from Actelion Pharmaceuticals Elililly, Pfizer and Bayer. CA currently receives grant funding from Stiftung Kinderherz (2511-10-13-001) and Behring-Röntgen-Stiftung (59-0018).

This Heart supplement was produced with support from an unrestricted educational grant from Actelion Pharmaceuticals Germany GmbH, Bayer Pharma AG, and Pfizer Inc. None of these organisations had any influence on the composition of the writing group or the content of the articles published in this supplement. Open Access publication of this article was sponsored by Actelion Pharmaceuticals Germany GmbH.

Provenance and peer review Commissioned; externally peer reviewed.

Open Access This is an Open Access article distributed in accordance with the Creative Commons Attribution Non Commercial (CC BY-NC 4.0) license, which permits others to distribute, remix, adapt, build upon this work non-commercially, and license their derivative works on different terms, provided the original work is properly cited and the use is non-commercial. See: http://creativecommons.org/ licenses/by-nc/4.0/

\section{REFERENCES}

1 Diller G-P, Kempny A, Inuzuka R, et al. Survival prospects of treatment naive patients with Eisenmenger: a systematic review of the literature and report of own experience. Heart 2014;100:1366-72.

2 Simonneau G, Gatzoulis MA, Adatia I, et al. Updated clinical classification of pulmonary hypertension. J Am Coll Cardiol 2013;62:D34-41.

3 Lammers AE, Apitz C, Zartner $\mathrm{P}$, et al. Diagnostics, monitoring and outpatient care in children with suspected pulmonary hypertension/ paediatric pulmonary hypertensive vascular disease. Expert consensus statement on the diagnosis and treatment of paediatric pulmonary hypertension. The European Paediatric Pulmonary Vascular Disease Network, endorsed by ISHLT and DGPK. Heart 2016;102:ii1-13.

4 Cerro MJD, Abman SH, Diaz G, et al. A consensus approach to the classification of pediatric pulmonary hypertensive vascular disease: report from the PVRI Paediatric Taskforce, Panama 2011. Pulm Circ 2011;1:286-98.

5 van Albada ME, Berger RMF. Pulmonary arterial hypertension in congenital cardiac disease - the need for refinement of the Evian-Venice classification. Cardiol Young 2008; 18:10-17

6 Schulze-Neick I, Beghetti M. Classifying pulmonary hypertension in the setting of the congenitally malformed heart-cleaning up a dog's dinner. Cardiol Young 2008:18:22-5.

7 Duffels MGJ, Engelfriet PM, Berger RMF, et al. Pulmonary arterial hypertension in congenital heart disease: an epidemiologic perspective from a Dutch registry. Int J Cardiol 2007;120:198-204.

8 Steele PM, Fuster V, Cohen M, et al. Isolated atrial septal defect with pulmonary vascular obstructive disease-long-term follow-up and prediction of outcome after surgical correction. Circulation 1987;76:1037-42.

9 Engelfriet PM, Duffels MGJ, Möller T, et al. Pulmonary arterial hypertension in adults born with a heart septal defect: the Euro Heart Survey on adult congenital heart disease. Heart 2007:93:682-7.

10 Barst RJ, McGoon MD, Elliott CG, et al. Survival in childhood pulmonary arterial hypertension: insights from the registry to evaluate early and long-term pulmonary arterial hypertension disease management. Circulation 2012;125:113-22.

11 Hansmann G, Apitz C, Abdul-Khaliq H, et al. Executive Summary. Expert Consensus Statement on the Diagnosis and Treatment of Paediatric Pulmonary Hypertension. Expert consensus statement on the diagnosis and treatment of paediatric pulmonary hypertension. The European Paediatric Pulmonary Vascular Disease Network, endorsed by ISHLT and DGPK. Heart 2016;102:ii86-100.

12 Ivy DD, Abman SH, Barst RJ, et al. Paediatric pulmonary hypertension. J Am Coll Cardiol 2013;62:D117-26.

13 Lopes AA, Barst RJ, Haworth SG, et al. Repair of congenital heart disease with associated pulmonary hypertension in children: what are the minimal investigative procedures? Consensus statement from the Congenital Heart Disease and Paediatric Task Forces, Pulmonary Vascular Research Institute (PVRI). Pulm Circ 2014:4:330-41.

14 Rosenzweig EB, Barst RJ. Congenital heart disease and pulmonary hypertension: pharmacology and feasibility of late surgery. Prog Cardiovasc Dis 2012;55:128-33.

15 Haworth SG, Hislop AA. Treatment and survival in children with pulmonary arterial hypertension: the UK Pulmonary Hypertension Service for Children 2001-2006. Heart 2009:95:312-17.

16 Oechslin E, Mebus S, Schulze-Neick I, et al. The adult patient with Eisenmenger syndrome: a medical update after dana point part III: specific management and surgical aspects. Curr Cardiol Rev 2010;6:363-72.

17 Diller G-P, Alonso-Gonzalez R, Dimopoulos K, et al. Disease targeting therapies in patients with Eisenmenger syndrome: response to treatment and long-term efficiency. Int J Cardiol 2013;167:840-7.

18 Tay ELW, Peset A, Papaphylactou M, et al. Replacement therapy for iron deficiency improves exercise capacity and quality of life in patients with cyanotic 
congenital heart disease and/or the Eisenmenger syndrome. Int J Cardiol 2011;151:307-12.

19 Van De Bruaene A, Delcroix M, Pasquet A, et al. Iron deficiency is associated with adverse outcome in Eisenmenger patients. Eur Heart J 2011;32:2790-9.

20 Broberg CS, Bax BE, Okonko DO, et al. Blood viscosity and its relationship to iron deficiency, symptoms, and exercise capacity in adults with cyanotic congenital heart disease. J Am Coll Cardiol 2006;48:356-65.

21 Bowyer JJ, Busst CM, Denison DM, et al. Effect of long term oxygen treatment at home in children with pulmonary vascular disease. Br Heart J 1986;55:385-90.

22 Sandoval J, Aguirre JS, Pulido T, et al. Nocturnal oxygen therapy in patients with the Eisenmenger syndrome. Am J Respir Crit Care Med 2001;164:1682-7.

23 Sandoval J, Santos LE, Córdova J, et al. Does anticoagulation in Eisenmenger syndrome impact long-term survival? Congenit Heart Dis 2012;7:268-76.

24 Broberg CS, Ujita M, Prasad S, et al. Pulmonary arterial thrombosis in eisenmenger syndrome is associated with biventricular dysfunction and decreased pulmonary flow velocity. J Am Coll Cardiol 2007;50:634-42.

25 Douwes JM, van Loon RLE, Hoendermis ES, et al. Acute pulmonary vasodilator response in paediatric and adult pulmonary arterial hypertension: occurrence and prognostic value when comparing three response criteria. Eur Heart J 2011;32:3137-46.

26 Hill KD, Lim DS, Everett $A D$, et al. Assessment of pulmonary hypertension in the pediatric catheterization laboratory: current insights from the Magic registry. Catheter Cardiovasc Interv 2010;76:865-73.

27 Apitz C, Reyes JT, Holtby $\mathrm{H}$, et al. Pharmacokinetic and hemodynamic responses to oral sildenafil during invasive testing in children with pulmonary hypertension. J Am Coll Cardiol 2010;55:1456-62.

28 Apitz C, Zimmermann R, Kreuder J, et al. Assessment of pulmonary endothelial function during invasive testing in children and adolescents with idiopathic pulmonary arterial hypertension. J Am Coll Cardiol 2012;60:157-64.

29 Giglia TM, Humpl T. Preoperative pulmonary hemodynamics and assessment of operability: is there a pulmonary vascular resistance that precludes cardiac operation? Pediatr Crit Care Med 2010;11:S57-69.

30 Celermajer DS, Cullen S, Deanfield JE. Impairment of endothelium-dependent pulmonary artery relaxation in children with congenital heart disease and abnormal pulmonary hemodynamics. Circulation 1993;87:440-6.

31 Beghetti M, Berger RMF, Schulze-Neick I, et al. Diagnostic evaluation of paediatric pulmonary hypertension in current clinical practice. Eur Respir J 2013;42:689-700.

32 Guazzi M, Adams V, Conraads V, et al. EACPR/AHA Joint Scientific Statement. Clinical recommendations for cardiopulmonary exercise testing data assessment in specific patient populations. Eur Heart J 2012;33:7-2927.

33 Galié N, Humbert M, Vachiery J-L, et al. 2015 ESC/ERS Guidelines for the diagnosis and treatment of pulmonary hypertension. The Joint Task Force for the Diagnosis and Treatment of Pulmonary Hypertension of the European Society of Cardiology (ESC) and the European Respiratory Society (ERS): Endorsed by: Association for European Paediatric and Congenital Cardiology (AEPC), International Society for Heart and Lung Transplantation (ISHLT). Eur Heart J 2016;37:67-119.

34 Koestenberger M, Apitz C, Abdul-Khaliq H, et al. Transthoracic echocardiography for the evaluation of children and adolescents with suspected or confirmed pulmonary hypertension. Expert consensus statement on the diagnosis and treatment of paediatric pulmonary hypertension. The European Paediatric Pulmonary Vascular Disease Network, endorsed by ISHLT and DGPK. Heart 2016;102:ii14-22.

35 Latus $\mathrm{H}$, Kuehne T, Beerbaum P, et al. Cardiac magnetic resonance and computed tomography imaging in children with suspected or confirmed pulmonary hypertension/pulmonary hypertensive vascular disease. Expert consensus statement on the diagnosis and treatment of paediatric pulmonary hypertension. The European Paediatric Pulmonary Vascular Disease Network, endorsed by ISHLT and DGPK. Heart 2016;102:ii30-5

36 Adatia I, Kothari SS, Feinstein JA. Pulmonary hypertension associated with congenital heart disease: pulmonary vascular disease: the global perspective. Chest 2010;137:52S-61S.

37 van Riel ACMJ, Schuuring MJ, van Hessen ID, et al. Contemporary prevalence of pulmonary arterial hypertension in adult congenital heart disease following the updated clinical classification. Int J Cardiol 2014;174:299-305.

38 Manes A, Palazzini $M$, Leci $E$, et al. Current era survival of patients with pulmonary arterial hypertension associated with congenital heart disease: a comparison between clinical subgroups. Eur Heart J 2014:35:716-24.

39 Koestenberger M, Burmas A, Ravekes W, et al. Echocardiographic Reference Values for Right Atrial Size in Children with and without Atrial Septal Defects or Pulmonary Hypertension. Pediatr Cardiol (Published Online First: 26 December 2015).

40 Hansmann G, Apitz C. Treatment of children with pulmonary hypertension. Expert consensus statement on the diagnosis and treatment of paediatric pulmonary hypertension. The European Paediatric Pulmonary Vascular Disease Network, endorsed by ISHLT and DGPK. Heart 2016;102:ii67-85.

41 Rosenkranz S, Ghofrani H-A, Beghetti M, et al. Riociguat for pulmonary arterial hypertension associated with congenital heart disease. Heart 2015;101:1792-9.

42 Apitz C, Hansmann G, Schranz D. Genetic testing and blood biomarkers in paediatric pulmonary hypertension. Expert consensus statement on the diagnosis and treatment of paediatric pulmonary hypertension. The European Paediatric Pulmonary Vascular Disease Network, endorsed by ISHLT and DGPK. Heart 2016;102:ii23-9.
43 Dimopoulos K, Inuzuka R, Goletto $S$, et al. Improved survival among patients with Eisenmenger syndrome receiving advanced therapy for pulmonary arterial hypertension. Circulation 2010;121:20-5.

44 Rich S, Rabinovitch $M$. Diagnosis and treatment of secondary (non-category 1) pulmonary hypertension. Circulation 2008;118:2190-9.

45 Lévy M, Maurey C, Celermajer DS, et al. Impaired apoptosis of pulmonary endothelial cells is associated with intimal proliferation and irreversibility of pulmonary hypertension in congenital heart disease. J Am Coll Cardiol 2007:49:803-10

46 Hilgendorff A, Apitz C, Bonnet D, et al. Pulmonary hypertension associated with acute or chronic lung diseases in the preterm and term neonate and infant. Expert consensus statement on the diagnosis and treatment of paediatric pulmonary hypertension. The European Paediatric Pulmonary Vascular Disease Network, endorsed by ISHLT and DGPK. Heart 2016;102:ii49-56.

47 Lopes AA, O'Leary PW. Measurement, interpretation and use of haemodynamic parameters in pulmonary hypertension associated with congenital cardiac disease. Cardiol Young 2009;19:431-5.

48 Barst RJ, Ertel SI, Beghetti M, et al. Pulmonary arterial hypertension: a comparison between children and adults. Eur Respir J 2011:37:665-77.

49 Barst RJ, McGoon M, Torbicki A, et al. Diagnosis and differential assessment of pulmonary arterial hypertension. J Am Coll Cardiol 2004;43:40S-7S.

50 Kaestner M, Schranz D, Warnecke G, et al. Pulmonary hypertension in the intensive care unit. Expert consensus statement on the diagnosis and treatment of paediatric pulmonary hypertension. The European Paediatric Pulmonary Vascular Disease Network, endorsed by ISHLT and DGPK. Heart 2016;102:ii57-66.

51 Lammers AE, Haworth SG, Diller G-P. Atrial septostomy in patients with pulmonary hypertension: should it be recommended? Expert Rev Respir Med 2011:5:363-76.

52 Latus H, Apitz C, Schmidt D, et al. Potts shunt and atrial septostomy in pulmonary hypertension caused by left ventricular disease. Ann Thorac Surg 2013;96: 317-19.

53 Blanc J, Vouhé $P$, Bonnet D. Potts shunt in patients with pulmonary hypertension. N Engl J Med 2004;350:623-623.

54 Gorenflo M, Gu H, Xu Z. Peri-operative pulmonary hypertension in paediatric patients: current strategies in children with congenital heart disease. Cardiology 2010;116:10-17.

55 Gorenflo M. Perioperative care in patients with pulmonary hypertension after cardiac surgery: clinical management, outcome and future clinical research. Results from an expert meeting. Cardiology 2010;116:1-2.

56 Novick WM, Sandoval N, Lazorhysynets VV, et al. Flap valve double patch closure of ventricular septal defects in children with increased pulmonary vascular resistance. Ann Thorac Surg 2005:79:21-8.

57 Galiè N, Beghetti M, Gatzoulis MA, et al. Bosentan therapy in patients with Eisenmenger syndrome: a multicenter, double-blind, randomized, placebo-controlled study. Circulation 2006;114:48-54.

58 Galiè N, Manes $\mathrm{A}$, Palazzini $\mathrm{M}$, et al. Management of pulmonary arterial hypertension associated with congenital systemic-to-pulmonary shunts and Eisenmenger's syndrome. Drugs 2008;68:1049-66.

59 Gatzoulis MA, Beghetti M, Galiè N, et al. Longer-term bosentan therapy improves functional capacity in Eisenmenger syndrome: results of the BREATHE-5 open-label extension study. Int J Cardiol 2008;127:27-32.

60 Iversen $K$, Jensen AS, Jensen TV, et al. Combination therapy with bosentan and sildenafil in Eisenmenger syndrome: a randomized, placebo-controlled, double-blinded trial. Eur Heart J 2010;31:1124-31.

61 Baumgartner $\mathrm{H}$, Bonhoeffer $\mathrm{P}$, De Groot NMS, et al. ESC Guidelines for the management of grown-up congenital heart disease (new version 2010). Eur Heart $J$ 2010;31:2915-57.

62 Rhodes CJ, Howard LS, Busbridge M, et al. Iron deficiency and raised hepcidin in idiopathic pulmonary arterial hypertension: clinical prevalence, outcomes, and mechanistic insights. J Am Coll Cardiol 2011;58:300-9.

63 Apostolopoulou SC, Papagiannis J, Rammos S. Bosentan induces clinical, exercise and hemodynamic improvement in a pre-transplant patient with plastic bronchitis after Fontan operation. J Heart Lung Transplant 2005;24:1174-6.

64 Goldberg DJ, French B, McBride MG, et al. Impact of oral sildenafil on exercise performance in children and young adults after the fontan operation: a randomized, double-blind, placebo-controlled, crossover trial. Circulation 2011;123:1185-93.

65 Giardini A, Balducci A, Specchia S, et al. Effect of sildenafil on haemodynamic response to exercise and exercise capacity in Fontan patients. Eur Heart J 2008:29:1681-7.

66 Ovaert $C$, Thijs $D$, Dewolf $D$, et al. The effect of bosentan in patients with a failing Fontan circulation. Cardiol Young 2009:19:331-9.

67 Hirono K, Yoshimura N, Taguchi M, et al. Bosentan induces clinical and hemodynamic improvement in candidates for right-sided heart bypass surgery. J Thorac Cardiovasc Surg 2010;140:346-51.

68 Beghetti M. Fontan and the pulmonary circulation: a potential role for new pulmonary hypertension therapies. Heart 2010;96:911-16.

69 Hebert A, Jensen AS, Idorn L, et al. The effect of bosentan on exercise capacity in Fontan patients; rationale and design for the TEMPO study. BMC Cardiovasc Disord 2013;13:36. 